Attilio Mastrocinque

\title{
The Mysteries of Mithras
}

\section{A Different Account}

[Die Mysterien des Mithras. Eine andere Darstellung.]

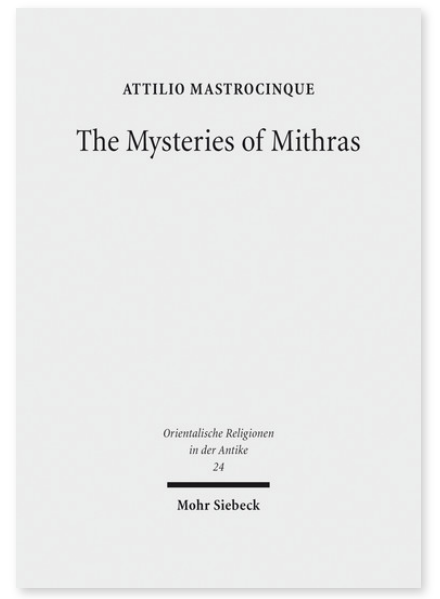

2017. XXI, 363 Seiten. ORA 24

ISBN 978-3-16-155118-5

DOI 10.1628/978-3-16-155118-5

eBook PDF 114,00€

ISBN 978-3-16-155112-3

Leinen $114,00 €$
Veröffentlicht auf Englisch.

Attilio Mastrocinque warnt in dieser Arbeit vor einer Annäherung an den Mithraismus basierend auf der Vorstellung, dass dieser mystische Kult dem Christentum ähnelt. Obwohl sowohl christliche als auch heidnische Autoren bezeugten, dass es mithrische Elemente übernommen hat, taten dies laut Attilio Mastrocinque nur einige gnostische Christen. Er wendet ein, dass die Ideologie und die Religion der Römischen Reichs bessere Hinweise darauf geben, wie man diese Frage angehen sollte, und behauptet auch, dass Virgil sich als wichtiger für das Verständnis der mithrischen Ikonographie herausstellt, als das Avesta. Die Bedeutung der zentralen Szene - der Tauroktonie - wird deutlich, wenn sie, als der zentrale Akt des römischen Triumphs, der des Bullenopfers, betrachtet wird, mit Mithras, dem Urheber dieses Erfolgs, in der Rolle des Siegers. Die Geschehnisse, die auf vielen Reliefs abgebildet werden, beziehen sich auf eine Prophezeiung, die Firmicus Maternus und anderen christlichen Polemikern bekannt war, und welche die Ankunft eines Erlösers, d.h. des ersten Kaisers, vorhersagt, wenn Saturn zurückkehrt und Apollo-Mithras regiert.

Attilio Mastrocinque Born 1952; 1975 Master; since 2002 Full Professor of Roman History at the University of Verona; 200810 president of Cultural Heritage courses at the University of Verona; 2005-15 Director of the Archaeological Mission at Grumentum (Lucania).

\section{Jetzt bestellen:}

https://mohrsiebeck.com/buch/the-mysteries-of-mithras-9783161551185?no_cache=1 order@mohrsiebeck.com

Telefon: $+49(0) 7071-923-17$

Telefax: $+49(0) 7071-51104$ 